\title{
Successful use of a fully covered metal stent for refractory bleeding from a duodenal cancer
}

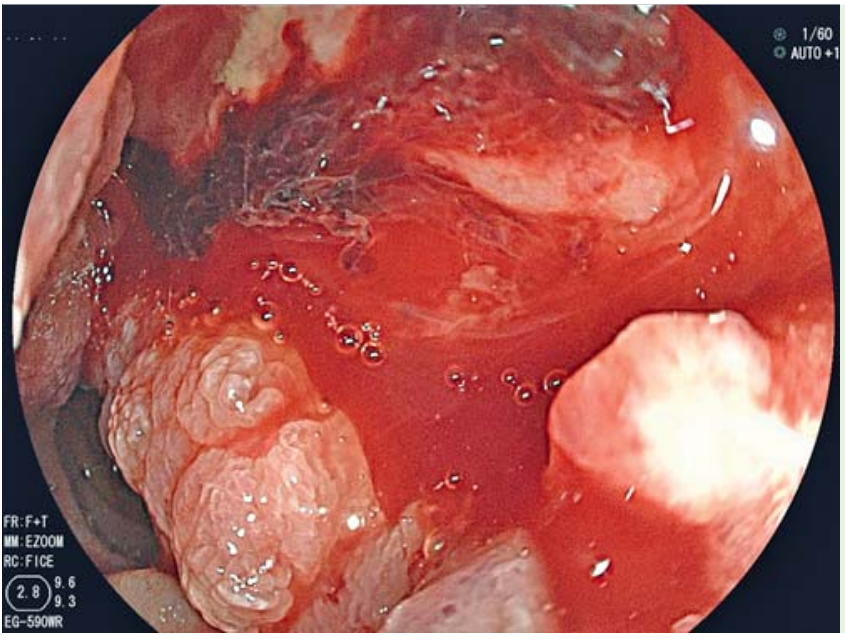

Fig. 1 Endoscopic view of a bleeding ulcerated tumor of the duodenum, successfully managed with a fully covered metal stent.

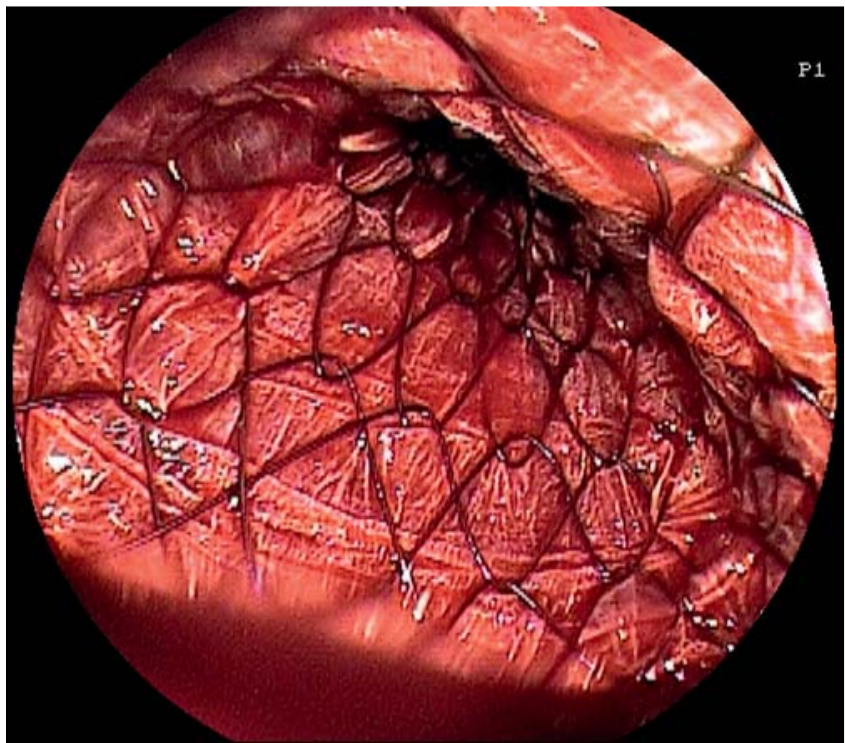

Fig. 3 Endoscopic view after the placement of a fully covered metal stent over the duodenal tumor.

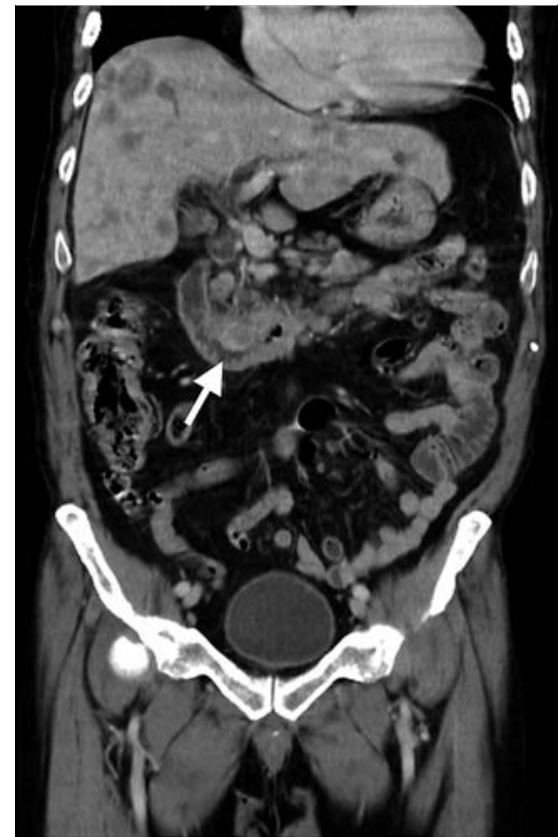

Fig. 2 Abdominal computed tomography reveals multiple hepatic tumors and an ulcerative tumor in the duodenum (arrow).

Korea) for tamponade of the bleeding tumor ( $\bullet$ Fig.3). Three days following placement of the metal stent, the passage of tarry stool started to decrease, and the patient resumed an oral diet. He was discharged 37 days after admission without further bleeding.

The use of an enteral metal stent is indicated mainly for the palliative management of malignant intestinal tract obstruction in patients with advanced malignancy of the esophagus, duodenum, stomach, pancreas, or colon [1]. Fully covered metal stents have also been used to treat esophageal perforation [2] and variceal bleeding [3]. The present case demonstrates that a fully covered metal stent can be a salvage tool [4] for the management of bleeding duodenal cancer when conventional endoscopic measures fail.

Endoscopy_UCTN_Code_TTT_1AO_2AF

Competing interests: None 
Hsu-Heng Yen ${ }^{1,2}$, Yang-Yuan Chen ${ }^{3}$, Pei-Yuan Su ${ }^{1}$

${ }^{1}$ Endoscopy Center, Changhua Christian Hospital, Changhua, Taiwan

${ }^{2}$ College of Medicine, Chung Shan Medical University, Taichung, Taiwan

${ }^{3}$ Department of Gastroenterology, China Medical University Hospital, Taichung, Taiwan

\section{References}

1 Kochar $R$, Shah $N$. Enteral stents: from esophagus to colon. Gastrointest Endosc 2013; 78: 913-918

2 Yen $H H$, Chen YY. Pneumomediastinum, pneumoperitoneum, pneumoretroperitoneum, and subcutaneous emphysema after ultrathin endoscopy. Endoscopy 2011; 43 (Suppl. 02): E49-E50

3 Holster IL, Kuipers EJ, van Buuren HR et al. Self-expandable metal stents as definitive treatment for esophageal variceal bleeding. Endoscopy 2013; 45: 485-488

4 D'Souza PM, Sandha GS, Teshima CW. Refractory bleeding from a malignant duodenal ulcer treated with placement of a fully-covered gastroduodenal stent. Dig Dis Sci 2013; 58: $3359-3361$

\section{Bibliography}

Dol http://dx.doi.org/

10.1055/s-0034-1391130

Endoscopy 2015; 47: E34-E35

(c) Georg Thieme Verlag KG

Stuttgart · New York

ISSN 0013-726X

\section{Corresponding author}

Hsu-Heng Yen, MD

Endoscopy Center

Changhua Christian Medical Center

135 Nanshio Street

Changhua 500

Taiwan

Fax: 886-4-7238595

91646@cch.org.tw 